\title{
XRD and optical microscopic studies of Co(III) complexes containing 5-cyano-6-(4-pyridyl)-2-thiouracil, thymine and adenine bases
}

\author{
LALLAN MISHRA*, BRAJESH PATHAK and R K MANDAL ${ }^{\dagger}$ \\ Department of Chemistry, ${ }^{\dagger}$ Department of Metallurgical Engineering, Banaras Hindu University, Varanasi 221005, \\ India
}

MS received 5 September 2000; revised 23 March 2001

\begin{abstract}
Multifunctional ligand 5-cyano-6-(-4-pyridyl)-2-thiouracil (L) was prepared and allowed to react with trans $\left[\mathrm{Co}(\mathrm{en})_{2} \mathrm{Cl}_{2}\right]^{+} \mathrm{Cl}^{-}$resulting into $\left[\mathrm{Co}(\mathrm{en})_{2} \mathrm{LCl}\right]^{2+} \cdot 2 \mathrm{Cl}^{-}$which upon further reaction with equimolar ratio of ligand $[\mathrm{L}]$ gave the complex $\left[\mathrm{Co}(\mathrm{en})_{2} \mathrm{~L}_{2}\right]^{3+} \cdot 3 \mathrm{Cl}^{-}$. These metal complexes were then separately reacted with thymine and adenine bases. Complexes thus prepared after characterization by their elemental analysis, FAB mass and spectral (IR, ${ }^{1} \mathrm{HNMR}$, UV-visible) data were studied for their powder X-ray diffraction and optical microscopic characteristics.
\end{abstract}

Keywords. Supramolecular; hydrogen-bonding; thymine; adenine.

\section{Introduction}

Self-assembly of molecules containing complementary hydrogen-bonding groups structurally related to those found in nucleotide bases are of current research interest in the area of supramolecular chemistry (Burrows et al 1995). Since non-covalent interactions play a special role in supramolecular chemistry (Lehn 1988, 1990), various supramolecular species have been synthesized by adopting the procedure of non-covalently assisted synthetic technique which primarily relies on the principle of stabilization provided by the interaction between recognition site incorporated within precursors (Muller-Dethlefs and Hobza 2000). In this context, the development of multifunctional ligand leading to the formation of the metal complexes capable of recognizing nucleotide bases by means of hydrogen-bonding have been considered quite promising. Metal based supramolecular complexes have also been used for inducing the formation of supramolecular mesophase and self-assembled nanostructure (Burrows et al 1995). Additionally, rhodium acetate dimer and related complexes have shown good antitumour activity (Clarke et al 1999), so cobalt being congener of rhodium was thought to be of great biological relevance.

Thus on the basis of above reports it was considered worthwhile to synthesize some Co(III) complexes bearing multifunctional ligand (L) scheme 1 and to attach them with adenine and thymine bases for their solid states structural studies using X-ray powder diffraction and optical microscopy techniques.

\footnotetext{
*Author for correspondence
}

\section{Experimental}

5-Cyano-6-(4-pyridyl)-2-thiouracil (L) and trans $\left[\mathrm{Co}(\mathrm{en})_{2}\right.$ $\left.\mathrm{Cl}_{2}\right]^{+} \cdot \mathrm{Cl}^{-}$were prepared by the reported procedures of Upadhyay and Ram (1999) and Haworth and Elsen (1974) respectively.

Synthetic strategy reported by Mishra et al (2001) is shown in scheme 1 . In this procedure, equimolar ratio of $\mathrm{L}$ and $\left[\mathrm{Co}(\mathrm{en})_{2} \mathrm{Cl}_{2}\right]^{+} \mathrm{Cl}^{-}$were allowed to react in methanol $(\sim 10 \mathrm{ml})$ which gave the initial product identified as $\left[\mathrm{Co}(\mathrm{en})_{2} \mathrm{LCl}\right]^{2+} \cdot 2 \mathrm{Cl}^{-}$which upon further reaction with equimolar ratio $(1: 1)$ of $\mathrm{L}$ in methanol containing few drops of DMSO gave another product identified as $\left[\mathrm{Co}(\text { en })_{2} \mathrm{~L}_{2}\right]^{3+} \cdot 3 \mathrm{Cl}^{-}$. These complexes were then further allowed to react separately with $1: 1$ and $1: 2$ molar ratio of thymine, however $1: 3$ molar ratio of the complexes $\left[\mathrm{Co}(\mathrm{en})_{2} \mathrm{LCl}\right]^{2+} \cdot 2 \mathrm{Cl}^{-}$and adenine in similar condition yielded the complex $\left[\mathrm{Co}(\mathrm{en})_{2} \mathrm{LA}_{3}\right]^{3+} \cdot 3 \mathrm{Cl}^{-}$.

\section{Results and discussion}

Details of the instruments used for spectral (IR, UVvisible, ${ }^{1} \mathrm{HNMR}$ ) studies have already been reported elsewhere (Mishra et al 2001), however, powder X-ray diffraction data were collected on PW1717 and optical microscopic study was done using Leitz optical microscope.

Synthetic strategy of the complexes as shown in scheme 1 indicated the different types of the complexes used in present study. The composition of the complexes has been assigned on the basis elemental analysis and FAB mass data (Mishra et al 2001). Complexes were found to decompose after heating above room temperature. The structure of the complexes, are however, supported by their spectroscopic data. 

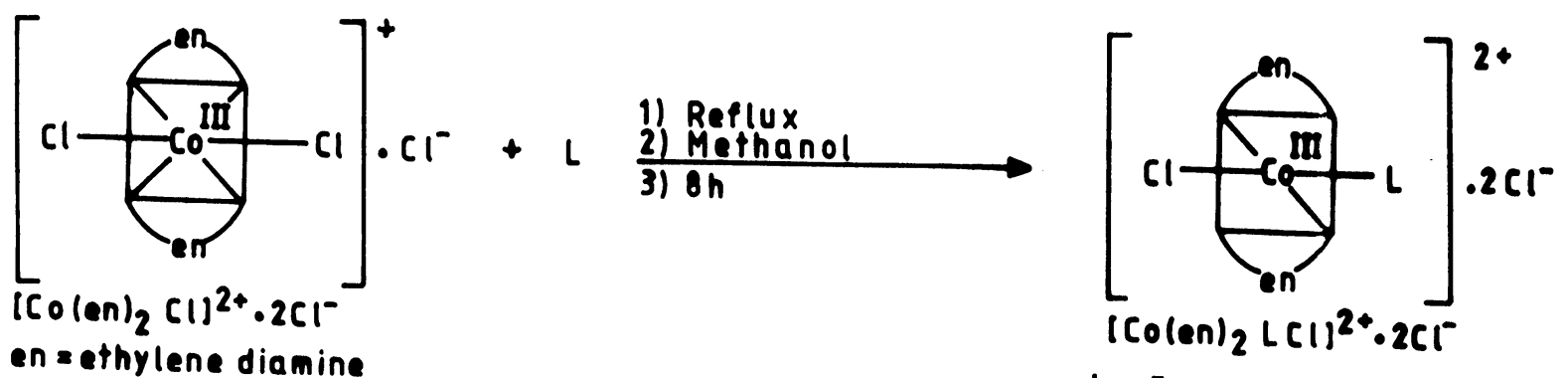

$\begin{aligned} L= & \text { 5-cyano-6-(4-pyridyl)- } \\ & \text { 2-thiouracil }\end{aligned}$
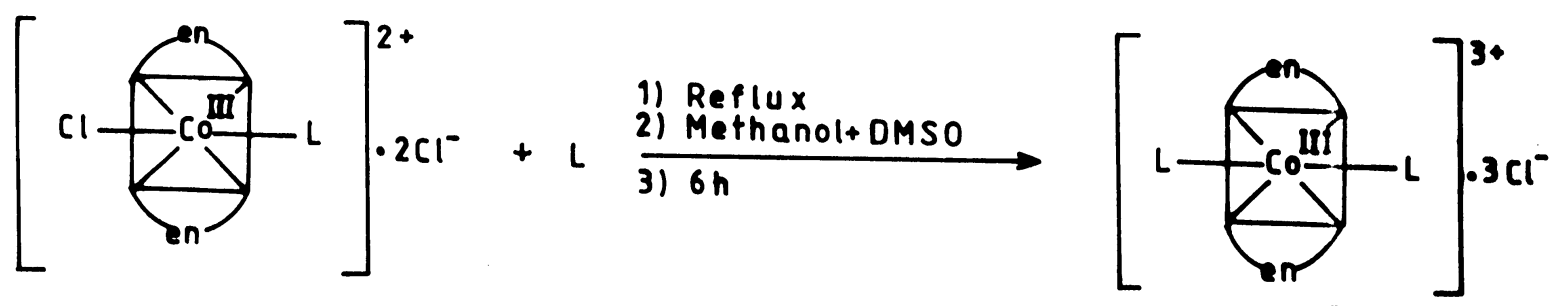

$\left(\mathrm{Co}(\mathrm{en})_{2} \mathrm{~L}_{2}\right)^{3+} \cdot 3 \mathrm{Cl}^{-}$
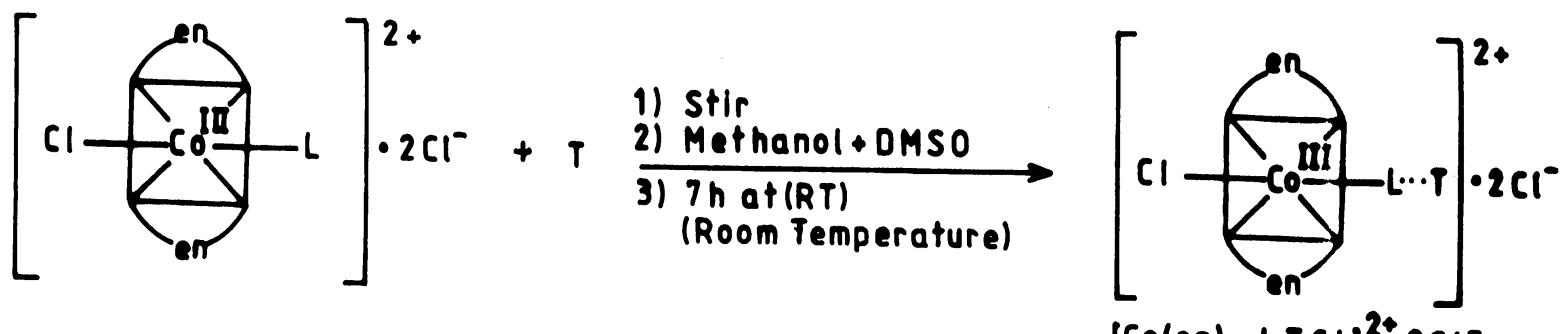
lColen) $2 L^{2}(1)^{2 *} \cdot 2 \mathrm{Cl}^{-}$
$T=$ Thymine
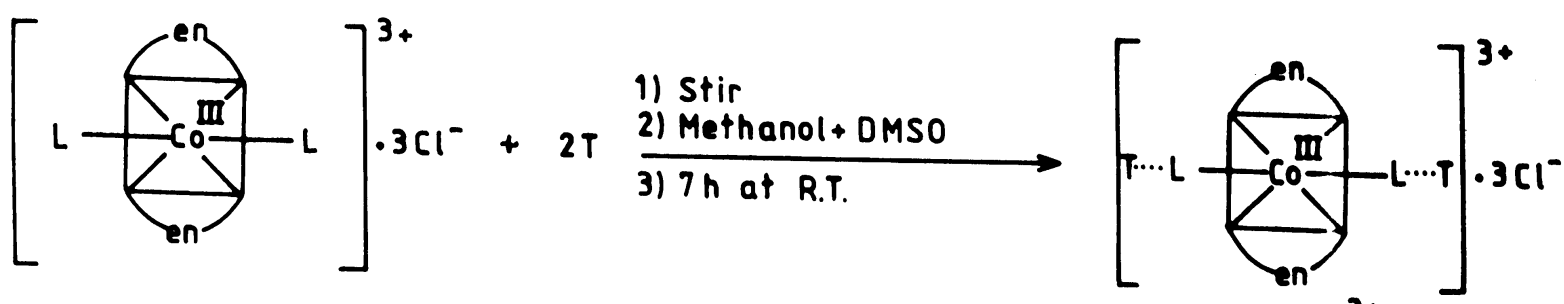

$\left[\mathrm{Co}(\mathrm{en})_{2} \mathrm{~L}_{2} \mathrm{~T}_{2}\right)^{3+} \cdot 3 \mathrm{Cl}^{-}$
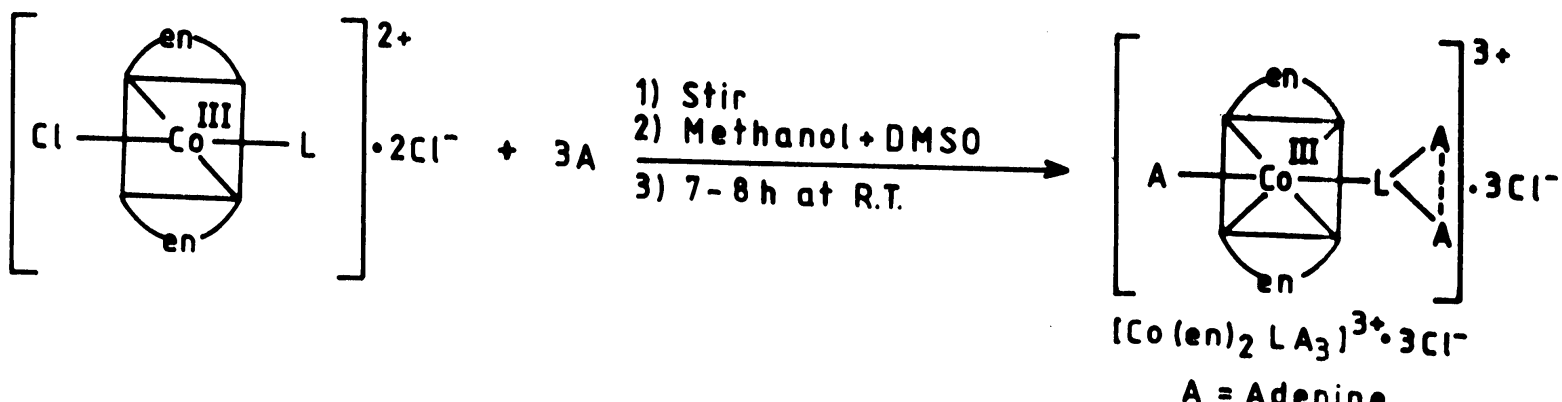

Scheme 1. Synthetic strategy adopted for the preparation of the complexes. 
From the IR spectra of the complexes peaks observed at $1610 \mathrm{~cm}^{-1}$ indicated the coordination of pyridyl group. However, lowering of the ligand peaks (1680, 3150 and $1125 \mathrm{~cm}^{-1}$ ) by $5-10 \mathrm{~cm}^{-1}$ was observed in the spectra of its complexes. Similarly lowering in $-\mathrm{NH}$ and $>\mathrm{C}=\mathrm{O}$ vibration of thymine and adenine in the spectra of the complexes supported their interaction with the ligand. However, $\vee \mathrm{C} \equiv \mathrm{N}\left(2210 \mathrm{~cm}^{-1}\right)$ of the ligand remained constant in the spectra of the complexes. Furthermore, the presence of thymine and adenine in the corresponding complexes was also supported by the observation of $-\mathrm{NH}$ and $-\mathrm{NH}_{2}$ protons at $\delta 10.6$ and 7.3 ppm respectively in their ${ }^{1}$ HNMR spectra.

From the visible spectrum of the complex, $\left[\mathrm{Co}(\mathrm{en})_{2}\right.$ $\mathrm{LCl}]^{2+} \cdot 2 \mathrm{Cl}^{-}$transitions observed at 480 and $504 \mathrm{~nm}$ were assigned to ${ }^{1} A_{1 \mathrm{~g}} \rightarrow{ }^{1} T_{2 \mathrm{~g}}$ and ${ }^{1} A_{1 \mathrm{~g}} \rightarrow{ }^{1} T_{1 \mathrm{~g}}$ respectively (Cotton et al 1999). The transition at lower energy (504 nm) was found to be split showing its trans configuration. However, red shift by $8-16 \mathrm{~nm}$ was observed in the spectra of the complexes.

Thus these spectral studies supported the structure of the complexes as shown in scheme 1 .

\subsection{XRD studies}

Calculated and experimental $d$ values $\left(d_{\text {cal }}\right),\left(d_{\text {obs }}\right)$, for the representative complex $\left[\mathrm{Co}(\mathrm{en})_{2} \mathrm{LTCl}\right]^{2+} \cdot 2 \mathrm{Cl}^{-}$are presented in table 1 together with their lattice parameters calculated by Ito's method (Azaroff and Buerger 1958). Majority of the X-ray powder diffraction peaks have been indexed by the crystal system having lattice parameters indicated in table 2. It has been noted from this table that all complexes except $\left[\mathrm{Co}(\mathrm{en})_{2} \mathrm{LCl}\right]^{2+} \cdot 2 \mathrm{Cl}^{-}$displayed orthorhombic crystal systems whereas $\left[\mathrm{Co}(\mathrm{en})_{2} \mathrm{LCl}\right]^{2+} \cdot 2 \mathrm{Cl}^{-}$has tetragonal system. Root means square deviation of $d$ values $(R)$ (Cullity 1978) for these systems are also shown in table 2. The low value of $R$ for some of the complexes supported that the coherently scattering domain size $(t)$ (Cullity 1978) are large, though lie well below to that expected for normal size (>1000 ̊) of crystallites. For $\left[\mathrm{Co}(\mathrm{en})_{2} \mathrm{LCl}\right]^{2+} \cdot 2 \mathrm{Cl}^{-}$in particular, this size is $\sim 10 \mathrm{~nm}$ and may be behaving like a nanocrystalline complex having large volume fractions of homophase or heterophase boundaries, however, we could not comment on the nature of above interfaces as it require high resolution electron microscopic studies. We may conclude this discussion by stating that $\left[\mathrm{Co}(\mathrm{en})_{2} \mathrm{LCl}\right]^{2+} \cdot 2 \mathrm{Cl}^{-}$will have lot of structural defects vis-á-vis those of $\left[\mathrm{Co}(\mathrm{en})_{2} \mathrm{LTCl}\right]^{2+} \cdot 2 \mathrm{Cl}^{-}$and $\left[\mathrm{Co}(\mathrm{en})_{2} \mathrm{~L}_{2} \mathrm{~T}_{2}\right]^{3+} \cdot 3 \mathrm{Cl}^{-}$where the $t$ values are relatively larger. We have made this statement owing to the fact that property of these complexes in the solid state will be dependent on such defects as is true for many other class of materials.

The change in the crystal structure from tetragonal to orthorhombic for $\left[\mathrm{Co}(\mathrm{en})_{2} \mathrm{LCl}\right]^{2+} \cdot 2 \mathrm{Cl}^{-}$and $\left[\mathrm{Co}(\mathrm{en})_{2}\right.$ $\left.\mathrm{L}_{2}\right]^{3+} \cdot 3 \mathrm{Cl}^{-}$can be understood by recalling that number of ligands in $\left[\mathrm{Co}(\mathrm{en})_{2} \mathrm{~L}_{2}\right]^{3+} \cdot 3 \mathrm{Cl}^{-}$impart a more symmetric configuration through covalent bonding hence reducing the unit cell volume (lattice parameters in table 2). Furthermore, complexes other than the above displayed orthorhombic structures which could be attributed to the presence of weaker bonding (hydrogen-bonding) in them. We have invariably noticed that the peak widths in almost all the cases were higher than those introduced by instrumental broadening in XRD data which clearly indicated

Table 1. XRD data for a representative complex $\left[\mathrm{Co}(\mathrm{en})_{2} \mathrm{TCl}\right]^{2+} \cdot 2 \mathrm{Cl}^{-}$, $\lambda \sim 1.54 \AA$.

\begin{tabular}{|c|c|c|c|c|}
\hline Angle $(2 \theta)$ & $d$ value $(\AA)$ & $1 / d^{2}$ (obs.) & $1 / d^{2}$ (calcd.) & $h k l$ \\
\hline $6 \cdot 720$ & $13 \cdot 1429$ & $0 \cdot 0057$ & $0 \cdot 0057$ & 100 \\
\hline $8 \cdot 755$ & $10 \cdot 0920$ & $0 \cdot 0098$ & $0 \cdot 0098$ & 010 \\
\hline $13 \cdot 535$ & $6 \cdot 5368$ & $0 \cdot 0234$ & $0 \cdot 0234$ & 001 \\
\hline $15 \cdot 020$ & $5 \cdot 8937$ & $0 \cdot 0287$ & $0 \cdot 0291$ & 101 \\
\hline $20 \cdot 990$ & $4 \cdot 2289$ & 0.0559 & $0 \cdot 0563$ & 211 \\
\hline $22 \cdot 100$ & $4 \cdot 0190$ & 0.0619 & $0 \cdot 0619$ & 310 \\
\hline $26 \cdot 590$ & $3 \cdot 3496$ & $0 \cdot 0891$ & $0 \cdot 0883$ & 030 \\
\hline $26 \cdot 940$ & $3 \cdot 3069$ & $0 \cdot 0914$ & $0 \cdot 0913$ & 320 \\
\hline $29 \cdot 495$ & $3 \cdot 0260$ & $0 \cdot 1092$ & $0 \cdot 1091$ & 112 \\
\hline $30 \cdot 685$ & $2 \cdot 9113$ & $0 \cdot 1172$ & $0 \cdot 1174$ & 131 \\
\hline $32 \cdot 265$ & $2 \cdot 7723$ & $0 \cdot 1301$ & $0 \cdot 1318$ & 420 \\
\hline $33 \cdot 450$ & $2 \cdot 6767$ & $0 \cdot 1395$ & $0 \cdot 1385$ & 122 \\
\hline $42 \cdot 960$ & $2 \cdot 1036$ & $0 \cdot 2259$ & $0 \cdot 2254$ & 422 \\
\hline $43 \cdot 540$ & $2 \cdot 0769$ & $0 \cdot 2318$ & $0 \cdot 2318$ & 601 \\
\hline $44 \cdot 510$ & $2 \cdot 0339$ & $0 \cdot 2417$ & $0 \cdot 2416$ & 611 \\
\hline $47 \cdot 405$ & $1 \cdot 9162$ & $0 \cdot 2723$ & $0 \cdot 2730$ & 441 \\
\hline $50 \cdot 855$ & $1 \cdot 7940$ & $0 \cdot 3107$ & $0 \cdot 3118$ & 612 \\
\hline $55 \cdot 155$ & $1 \cdot 6639$ & $0 \cdot 3611$ & $0 \cdot 3621$ & 152 \\
\hline $58 \cdot 385$ & $1 \cdot 5793$ & 0.4009 & $0 \cdot 3999$ & 261 \\
\hline
\end{tabular}


size restriction on the coherently scattering domain. This is a characteristic which is true for all the complexes with large motifs. As such, systems would require more idealized condition of growth for producing defects free grains.

\subsection{Microstructural characterization}

Figures $1 \mathrm{a}$ and $\mathrm{b}$ depict the optical micrographs of $\mathrm{a}$ representative section of $\left[\mathrm{Co}(\mathrm{en})_{2} \mathrm{LCl}\right]^{2+} \cdot 2 \mathrm{Cl}^{-}$and $\left[\mathrm{Co}(\mathrm{en})_{2}\right.$ $\left.\mathrm{L}_{2}\right]^{3+} \cdot 3 \mathrm{Cl}^{-}$specimen in the form of a pellet of identical diameter $(1 \mathrm{~cm})$ and thickness $\sim 1-3 \mathrm{~mm}$. The usual technique for the preparation of surfaces for optical micrography has been adopted. We noted that there is a uniform matrix of $\left[\mathrm{Co}(\mathrm{en})_{2} \mathrm{LCl}\right]^{2+} \cdot 2 \mathrm{Cl}^{-}$over which smaller regions separated by a black-contrast from the background could be seen. This leads us to believe that we are dealing with two-phase material. It is to be remembered that some of the XRD peaks for this case could not be indexed based on tetragonal cell parameters (cf. 3.1). By taking these two observations into account we may assume that this minor phase dispersed over the regions (figure 1a) may be due to the formation of $\left[\mathrm{Co}(\mathrm{en})_{2}\right.$ $\left.\mathrm{L}_{2}\right]^{3+} \cdot 3 \mathrm{Cl}^{-}$in the system. However, in contrast to the above, a single phase formation of $\left[\mathrm{Co}(\mathrm{en})_{2} \mathrm{~L}_{2}\right]^{3+} \cdot 3 \mathrm{Cl}^{-}$ complex having rod morphologies in the form of a bundle is displayed (figure 1b). The orientation of this rod bundles are different which is clearly depicted in figure 1c. We further observed a centre marked as ' $A$ ' on the micrograph from where different branches are coming out. The smaller diameter of the rod is $\sim 1 \mu \mathrm{m}$ whereas the larger one has $\sim 3 \mu \mathrm{m}$ and the uniform morphologies throughout the specimen (figures $1 \mathrm{~b}-\mathrm{c}$ ), prove our point of formation of a single phase and supports the reliability of our indexing proposal based on the orthorhombic system of given parameters.

Furthermore, addition of a drop of acetone to one side of the pellet of $\left[\mathrm{Co}(\mathrm{en})_{2} \mathrm{~L}_{2}\right]^{3+} \cdot 3 \mathrm{Cl}^{-}$, brings changes in the morphologies of the above systems and is shown in figure 1d. This micrograph also depicts the interface between the rod bundle morphologies and those after treatment with acetone. This may happen owing to the attachment of acetone to systems most likely through hydrogen bonding. This statement could be substantiated by making comparison of the acetone treated $\left[\mathrm{Co}(\mathrm{en})_{2} \mathrm{~L}_{2}\right]^{3+} \cdot 3 \mathrm{Cl}^{-}$ specimen with that of $\left[\mathrm{Co}(\mathrm{en})_{2} \mathrm{~L}_{2} \mathrm{~T}_{2}\right]^{3+} \cdot 3 \mathrm{Cl}^{-}$(figure $1 \mathrm{e}$ ). The attachment of acetone with the ligand is quite possible as it possesses the groups like $>\mathrm{C}=\mathrm{O}$ needed for bonding with the complementary group present in the ligand system.

Upon comparison of optical micrographs of $\left[\mathrm{Co}(\mathrm{en})_{2}\right.$ $\mathrm{LTCl}]^{2+} \cdot 2 \mathrm{Cl}^{-}$(figure 1f) and $\left[\mathrm{Co}(\mathrm{en})_{2} \mathrm{LA}_{3}\right]^{3+} \cdot 3 \mathrm{Cl}^{-}$(figure $1 \mathrm{~g})$ with that of starting compound $\left[\mathrm{Co}(\mathrm{en})_{2} \mathrm{LCl}\right]^{2+} \cdot 2 \mathrm{Cl}^{-}$, network morphologies could be seen in above systems and the features are totally different from those seen in $\left[\mathrm{Co}(\mathrm{en})_{2} \mathrm{LCl}\right]^{2+} \cdot 2 \mathrm{Cl}^{-}$(figure 1a). This supports the formation of single phase in system $\left[\mathrm{Co}(\mathrm{en})_{2} \mathrm{LTCl}\right]^{2+} \cdot 2 \mathrm{Cl}^{-}$.

Table 2. Lattice parameters of the complexes.

\begin{tabular}{|c|c|c|c|c|c|}
\hline Complexes & $\begin{array}{c}\text { Root mean square } \\
\text { deviation of } d \text { values } \\
\text { (' } R \text { ') }\end{array}$ & $\begin{array}{l}\text { Crystal system and } \\
\text { lattice parameter } \\
\text { (尺) }\end{array}$ & $\begin{array}{c}\theta \text { (angle at maximum } \\
\text { intensity for the } \\
\text { phase) }\end{array}$ & $\begin{array}{l}\beta \text { (half width at } \\
\text { half maximum } \\
\times 10^{-3} \text { in radian) }\end{array}$ & $\begin{array}{c}t \text { (coherently } \\
\text { scattering domain } \\
\text { size) in } \AA\end{array}$ \\
\hline$\left[\mathrm{Co}(\mathrm{en})_{2} \mathrm{LCl}\right]^{2+} \cdot 2 \mathrm{Cl}^{-}$ & $6 \cdot 3$ & $\begin{aligned} & \text { Tetragonal } \\
& a=10 \cdot 19 \\
& b=10 \cdot 19 \\
& c=6 \cdot 01\end{aligned}$ & $4 \cdot 3$ & $13 \cdot 7$ & 101 \\
\hline$\left[\mathrm{Co}(\mathrm{en})_{2} \mathrm{~L}_{2}\right]^{3+} \cdot 3 \mathrm{Cl}^{-}$ & $7 \cdot 7$ & $\begin{array}{l}\text { Orthorhombic } \\
\qquad \begin{array}{c}a=10 \cdot 21 \\
b=7 \cdot 80 \\
c=5 \cdot 74\end{array}\end{array}$ & 11.4 & $4 \cdot 5$ & 312 \\
\hline$\left[\mathrm{Co}(\mathrm{en})_{2} \mathrm{LTCl}\right]^{2+} \cdot 2 \mathrm{Cl}^{-}$ & 4.9 & $\begin{array}{l}\text { Orthorhombic } \\
\qquad \begin{array}{c}a=13 \cdot 14 \\
b=10 \cdot 09 \\
c=6 \cdot 54\end{array}\end{array}$ & $14 \cdot 8$ & $2 \cdot 3$ & 621 \\
\hline$\left[\mathrm{Co}(\mathrm{en})_{2} \mathrm{LA}_{3}\right]^{3+} \cdot 3 \mathrm{Cl}^{-}$ & $10 \cdot 0$ & $\begin{array}{l}\text { Orthorhombic } \\
\qquad \begin{aligned} a & =9 \cdot 82 \\
b & =6 \cdot 41 \\
c & =6 \cdot 12\end{aligned}\end{array}$ & $13 \cdot 8$ & $3 \cdot 5$ & 410 \\
\hline$\left[\mathrm{Co}(\mathrm{en})_{2} \mathrm{~L}_{2} \mathrm{~T}_{2}\right]^{3+} \cdot 3 \mathrm{Cl}^{-}$ & $3 \cdot 0$ & $\begin{array}{l}\text { Orthorhombic } \\
\qquad \begin{array}{c}a=12.99 \\
b=9.36 \\
c=6.36\end{array}\end{array}$ & $3 \cdot 4$ & $2 \cdot 3$ & 603 \\
\hline
\end{tabular}



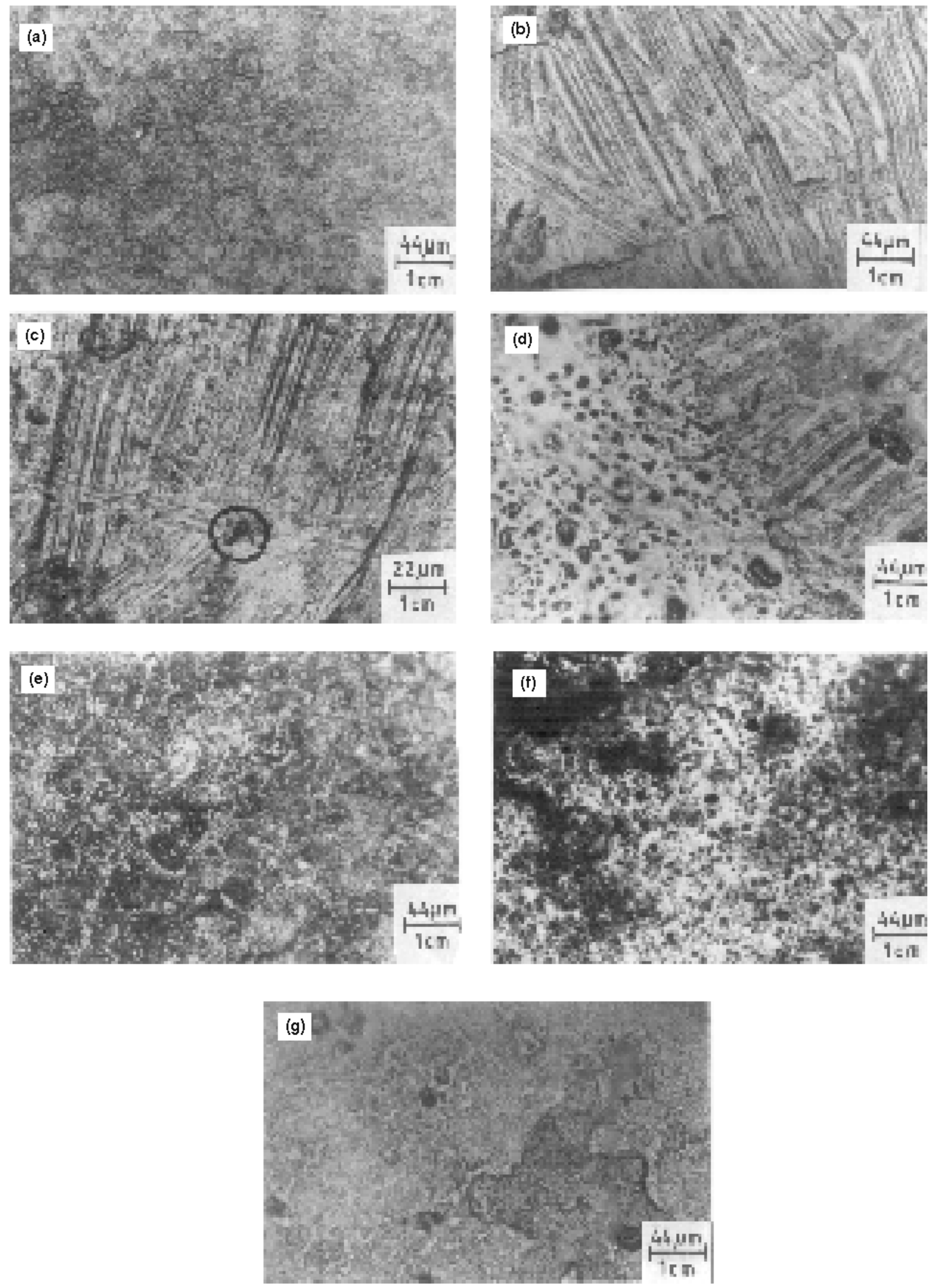

Figure 1. Optical micrograph of the complexes: (a) $[\mathrm{MLCl}]^{2+}$, (b) $\left[\mathrm{ML}_{2}\right]^{3+}$, (c) $\left[\mathrm{ML}_{2}\right]^{3+}$, (d) $\left[\mathrm{ML}_{2}\right]^{3+}$, containing acetone, (e) $\left[\mathrm{ML}_{2} \mathrm{~T}_{2}\right]^{3+}$, (f) $[\mathrm{MLTCl}]^{2+}$ and (g) $\left[\mathrm{MLA}_{3}\right]^{3+}, \mathrm{M}=\mathrm{Co}(\mathrm{en})_{2}$. 


\section{Conclusions}

We have observed that $\left[\mathrm{Co}(\mathrm{en})_{2} \mathrm{LCl}\right]^{2+} \cdot 2 \mathrm{Cl}^{-}$displays tetragonal structure with coherently scattering domain size of $\sim 10 \mathrm{~nm}$. However, $\left[\mathrm{Co}(\mathrm{en})_{2} \mathrm{LCl}\right]^{2+} \cdot 2 \mathrm{Cl}^{-}$after reaction with the ligand producing $\left[\mathrm{Co}(\mathrm{en})_{2} \mathrm{~L}_{2}\right]^{3+} \cdot 3 \mathrm{Cl}^{-}$showed orthorhombic structure. The microstructural characterizations of the solidified pellet have shown that $\left[\mathrm{Co}(\mathrm{en})_{2}\right.$ $\mathrm{LCl}]^{2+} 2 \mathrm{Cl}^{-}$possesses invariably two kinds of contrast, the contrast of the minor phase has been attributed to the formation of $\left[\mathrm{Co}(\mathrm{en})_{2} \mathrm{~L}_{2}\right]^{3+} \cdot 3 \mathrm{Cl}^{-}$in the system. In contrast to the above, the $\left[\mathrm{Co}(\mathrm{en})_{2} \mathrm{~L}_{2}\right]^{3+} \cdot 3 \mathrm{Cl}^{-}$complex has given uniform and identical contrast with rod morphology in the form of a bundle which supported the presence of single phase in this case. Further, the treatment of $\left[\mathrm{Co}(\mathrm{en})_{2}\right.$ $\left.\mathrm{L}_{2}\right]^{3+} \cdot 3 \mathrm{Cl}^{-}$complex with acetone leads to the transformation of the rod morphology and the changed features matched well with that of $\left[\mathrm{Co}(\mathrm{en})_{2} \mathrm{~L}_{2} \mathrm{~T}_{2}\right]^{3+} \cdot 3 \mathrm{Cl}^{-}$micrograph which has been explained on the basis of the similarity between the functional groups $(>\mathrm{C}=\mathrm{O})$ in both acetone and thymine.

\section{Acknowledgements}

We thank DST, New Delhi, for financial support, Dr V J Ram, CDRI, Lucknow, for providing microanalytical data and the anonymous referee for his valuable suggestions for improving the paper.

\section{References}

Azaroff L V and Buerger M Z (eds) 1958 The powder method in X-ray crystallography (New York: McGraw Hill) p. 119

Burrows A D, Chan-wing Chan, Chowdhary M M, McGrady J E, Michael D and Mingos D M P 1995 Chem. Soc. Rev. 325 and references therein

Clarke M J, Zhu F and Frasca D R 1999 Chem. Rev. 99 2522

Cotton F A, Wilkinson G, Murillo C A and Bochmann M (eds) 1999 Advanced inorganic chemistry (John Wiley) p. 825

Cullity B D (ed.) 1978 in Elements of X-ray diffraction (California: Addison Wesley) p. 284

Haworth D T and Elsen K M 1974 J. Chem. Edu. 300

Lehn J M 1988 Angew. Chem. Int. Ed. Engl. 2789

Lehn J M 1990 Angew. Chem. Int. Ed. Engl. 291304

Mishra L, Pathak B and Mandal R K 2001 Polyhedron (communicated)

Muller-Dethlefs K and Hobza P 2000 Chem. Rev. 100144

Upadhyay D N and Ram V J 1999 Indian J. Chem. B38 175 